\title{
PHYTOCHEMICAL CONSTITUENTS AND HYPOGLYCEMIC EFFECT OF GYMNEMIC ACID EXTRACTS FROM BIG AND SMALL LEAF VARIETIES OF Gymnema Sylvestre R.Br
}

\author{
Ramar Krishnamurthy, ${ }^{1}$ David Adedayo Animasaun ${ }^{1,2 *}$ Patel R. T.. ${ }^{1}$ and Rajashekhar \\ Ingalhalli ${ }^{1}$
}

\begin{abstract}
${ }^{1}$ C.G. Bhakta Institute of Biotechnology, Uka Tarsadia University, Bardoli, Surat, Gujarat, India 2Department of Plant Biology, University Of Ilorin, P.M.B 1515, Ilorin, Kwara State, Nigeria
\end{abstract}

Submitted: $22-01-2016$

Accepted: 03-04-2016

*Corresponding author Animasaun

Email:

animasaun.ad@unilorin. edu.ng
Revised: 05-02-2016

\begin{abstract}
Phytochemical and hypoglycemic effects of two varieties of Gymnema sylvestre were studied. The leaves of Big-leaf (MCL) and the small-leaf (ZMGL) varieties were grown in Uka Tarsadia University, Bardoli, India. Water, ethanol, methanol, petroleum ether, haxane and chloroform were used for phytochemical extraction from the dried leaves. Gymnemic acid was extracted and purified from the two varieties by Thin Layer Chromatography (TLC). Four groups of matured whisker rats (six per group) were induced with high-glucose level. Three groups were treated with standard drug glibenclamide $(5 \mathrm{mg} / \mathrm{kg})$, gymnemic acid extracts from MCL and ZMDL respectively while the fourth group served as experimental control. Hypoglycemic activities of extracts were evaluated using animals' blood sample. Result showed water and methanol are best solvents for phytochemical extraction from the plant and the yield is higher in ZMGL than MCL. Also, gymnemic acid yield varied. From the results, hypoglycemic activities from the animals' blood revealed that treatments from both MCL and ZMGL are not significantly different from standard drug glibenclamide. The study concluded that water or methanol is appropriate solvent for phytochemical extraction from $G$. sylvestre leaves and extract from both lines of the plant could be utilized to reduce blood glucose level
\end{abstract}

Keywords: phytochemical extraction, extraction solvents, gymnemic acid, hypoglycemic effects

\section{INTRODUCTION}

In the recent decades, with increasing urbanization and changing lifestyle, prevalence of diabetes is increasing at alarming rate. Diabetes is a chronic disorder of carbohydrate metabolism which results in high blood sugar levels (Gunjan et al, 2011). It is considered as one of the five leading cause of death in the world and it is estimated that diabetes would affect approximately 57 million people by the year 2025 (Grijesh et al., 2009). Treatment and management of human diseases using herbs is not new though; many traditional and orthodox medicines in use are derivatives of medicinal plants (Joseph and Jini, 2010). World Health Organization (WHO) has listed 21,000 plants of medicinal important around the world. Among these, about 150 species are used commercially on a fairly large scale (Zohary et al. 2000). India is a major exporter $(70 \%)$ of crude drug extract and (30\%) of finished products (ICMR, 2013) from herbs and medicinal plants.

Gymnema sylvestre (Retz) R. Br. is a slow growing, perennial, woody, climbing herb which belongs to Asclepiadaceae family. It grows in the tropical forests of Central and Southern India and can also be found in the tropical forests of Africa, Australia, Vietnam, Malaysia and Sri Lanka (Ye et al, 2000). The leaves of the plant when chewed deactivates the sweet bud's ability to detect sweet or sugary taste for several hours. Among the local people of India, the leaves are routinely used for control of diabetes and it is well recognized in traditional medicine as a remedy for diabetes mellitus; hence, the leaves are being sold along with the aerial parts as Gurmarbuti in most herbal markets in the country (Mitra, et al., 1995; Ankit, et al., 2010). 
G. sylvestre leaves contains several phytochemicals and gymnemic acids which is the most important constituent of the leaf extract have anti-diabetic, anti-sweetener and anti-inflammatory activities. (Liu et al., 1992; Nakamura et al., 2010). In addition, G. Sylvester leaf extract reduced high blood glucose in laboratory animals with potentials of treating diabetes in human and purified gymnemic acids are widely used as experimental reagents in taste physiology (Hellekant et al., 1998; Kanetkar et al., 2004). G. sylvestre has been reported to be safe in management of diabetes and short term uses of low doses may have unnoticeable side effects (Ogawa et al., 2004).

Considering the foregoing and the fact that orthodox drugs for the management of hyperglycemia may not be within the reach of the rural economy less buoyant people, there is need to investigate phytochemical compositions of $G$. sylvestre with the view to extract a cheaper, safe but effective herbal products for the management of hyperglycemia. The present study therefore seeks to compare the phytochemical constituents and gymnemic acid yield of two common varieties of $G$. syvestre and to investigate the effectiveness of (leaf extract) gymnemic acid hypoglycemia effects on whisker rats.

\section{MATERIAL AND METHODS}

The leaves of Big-leaf variety (MCL) and the Small-leaf variety (ZMGL from Research and Development Medicinal Plant Garden, Zandu Foundation for Health Care (ZFHC), Vapi, India) of Gymnema sylvestre grown in the Medicinal Plant Garden, College of Pharmacy, Uka Tarsadia University, Bardoli, Gujarat, India were collected and used for the study. Extracts from the two varieties were compared for amount of phytochemical constituents and gymnemic acid yield as well as their effecttiveness in the management of hyperglycemia in laboratory animals.

\section{Leaf extraction}

The leaves were thoroughly washed with tap water and shade dried for 15 days. $20 \mathrm{~g}$ of dried leaves and different solvents (water, ethanol, methanol, petroleum ether, hexane and chloroform) were used for extraction (Sofowora, 1993) to determine the most effective extraction solvent for phytochemical screening and physiochemical analysis of the leaves extract.

Qualitative and quantitative determination of bioactive compounds in the leaf extracts

Qualitative determinations for the presence of bioactive compounds were carried out. Saponins, carbohydrate, flavonoids, glycosides, alkaloids, terpenoids and tanins presence was determined by methods described by Sofowora (1993) and Kokare (1999).

The amounts of Tannin, Saponin, and Alkaloid present in the leaves extract for each of the lines was determined using the method described by Obadoni and Ochuko, 2001, Phenol and Flavonoid quantification was done according to Yadav et al. (2011), carbohydrates determination as described by Hedge and Hofreiter (1962), while protein was estimated based on Bradford (1976) procedure. The DPPH free radical scavenging activity of the leaf extract was determined according to the procedure of Gazella et al. (2012) and the estimation was done using the relationship $\mathrm{DPPH}$ scavenging activity $(\%)=\left\{1-\left(\mathrm{Abs}_{517}\right.\right.$ sample/Abs ${ }_{517} \mathrm{DPPH}$ solution) $\} \times 100$

\section{Physiochemical analysis}

Total ash, acid insoluble ash, water solubility, ether solubility and $\mathrm{pH}$ values of the leaf extracts for the two varieties of $G$. sylwestre were evaluated using the method of Khandelval (2008).

\section{Extraction of Gymnemic acid}

Different extraction methods were utilized for the extraction of Gymnemic acid from the powdered dried leaves of two varieties of G. sylvestre to compare the yield. Isolation of gymnemic acid was carried out according to Hooper (1987). Other methods were as described by Puratchimani and Jha (2004) and Gupta (2003). Methods for extraction of gymnemic acid and solvent system for thin layer chromatography with different $\mathrm{Rf}$ values (Table I).

\section{Hypoglycemic effect of gymnemic acid on experimental animals}

Healthy male whisker rats $(250-300 \mathrm{~g})$ were kept on $12 \mathrm{~h}$ light/dark cycle and had free access to food and water prior to laboratory experiment. The animals were acclimatized to 
Table I. Methods for extraction of gymnemic acid and solvent system for TLC.

\begin{tabular}{|c|c|c|c|c|}
\hline Method & Ref: & Staining reagent & Solvent system & Reference $\mathrm{Rf}$ value \\
\hline 1. & Hooper, 1987 & $\begin{array}{l}0.5 \% \text { Vanillin } \\
\text { stain }\end{array}$ & $\begin{array}{l}\text { Toluene: chloroform: } \\
\text { methanol (5:8:3) }\end{array}$ & 0.30 \\
\hline 2. & $\begin{array}{l}\text { Puratchimani } \\
\text { and Jha, } 2004\end{array}$ & $\begin{array}{l}0.5 \% \text { Vanillin } \\
\text { stain }\end{array}$ & $\begin{array}{l}\text { Chloroform : methanol } \\
(9: 1)\end{array}$ & 0.37 \\
\hline 3. & $\begin{array}{l}\text { Puratchimani } \\
\text { and Jha, } 2004\end{array}$ & Anisaldihyde & $\begin{array}{l}\text { Chloroform : isopropanol : } \\
\text { ammonia }(2: 8: 2)\end{array}$ & 0.45 \\
\hline 4. & Gupta 2003 & $\begin{array}{l}5 \% \text { methanolic } \\
\text { sulfuric acid }\end{array}$ & $\begin{array}{l}\text { Chloroform : methanol: } \\
\text { water }(8.86: 4.77: 1.36)\end{array}$ & $\begin{array}{c}0.07,0.13,0.27,0.36,0.48, \\
0.56,0.63,0.75\end{array}$ \\
\hline
\end{tabular}

the laboratory environment for an hour before the experiments. They were randomly distributed into four groups of 6 animals each. All experiments were conducted during the day (08.00-17.00h.). The procedures for testing the hypoglycemia effectiveness of the leaf extracts in comparison with standard drug of glibenclamide $5 \mathrm{mg} / \mathrm{kg}$ on the whisker rats was according to (Cretti et al., 2000). Blood samples were collected through retro-orbital plexus prior to commencement of treatment and at 30 minutes intervals up to a period of 150 minutes after glucose challenge. All the protocols were approved by the Institutional Animal Ethical Committee (IAEC), India.

\section{Statistical analysis}

The data obtained were subjected to the analysis of variance (ANOVA) using SPSS version 16.0 for Window Operating System and the effectiveness of the treatments was compared using Tukey's Multiple Comparison Test (TMCT). The level of significance difference between treatments was evaluated at the probability of $\mathrm{P}<0.05$.

\section{RESULTS AND DISCUSSION}

The qualitative analysis of crude samples from the two varieties of G. Sylwestres used for this study to determine presence of phytochemical compounds showed varied results for the presence or otherwise of phytochemical compounds with respect to different solvents of extraction as summarized (Table II). The result of preliminary screening of leaf extracts of G. Sylvestre for phytochemical using different solvent revealed that water and methanol are the best among tested solvents. The results implies that using water and methanol for extraction of phytochemical material does not affect the quality of the compounds in the extract. This may likely be as a result of simple polanic effect of the solvents. Ethanol extraction may also be applicable but less effective for phytochemical compounds such as saponin and tannin. Petroleum ether, hexane and chloroform would not produce good extract for phytochemical analysis of $G$. sylvestre leaf materials. The present result was in agreement with the report of Ajaiyoba (2000) who demonstrated that water and methanol were most effective for phytochemical extraction of Gynandropsis gynandra and Buchbolzia coriaceae.

The two varieties of $G$. sylvestre showed variations in amount of phytochemical compounds evaluated as summarized (Table III). Quantitative study of carbohydrates, proteins and secondary metabolites that were present in the leaf in $\mathrm{mg} / \mathrm{g}$ revealed that the quantity of saponin quantity was higher in MCL $(5.6 \mathrm{mg} / \mathrm{g})$, while ZMGL contained $5.2 \mathrm{mg} / \mathrm{g}$ of saponin. The differences in amount of phytochemical compounds present in the extract of the studied varieties could have arisen from different environmental and growth conditions of the plants since plants' chemical composition may be influenced by environmental factor. It was noted that the amount of phytochemical constituents of an extract depends on the chemical nature, quality, properties of constituents, the solvent employed, and the type of plant part and the method of extraction used (Trease and Evans 2005). 
Table II. Showing presence or otherwise of phytochemical compounds in the leaves extract of $G$. sylvestre using different solvents.

\begin{tabular}{|c|c|c|c|c|c|c|c|}
\hline Test & $\begin{array}{c}\text { Reagents } \\
\text { used }\end{array}$ & Water & Ethanol & Methanol & $\begin{array}{c}\text { Pet. } \\
\text { Ether }\end{array}$ & Hexane & Chloroform \\
\hline Saponin & $\begin{array}{l}\text { Foam } \\
\text { formation }\end{array}$ & + & - & + & + & - & - \\
\hline Tannin & $2 \% \mathrm{FeCl}_{3}$ & + & - & + & - & - & - \\
\hline Flavonoid & $2 \% \mathrm{NaOH}$ & - & + & + & - & - & - \\
\hline Carbohydrate & Benedict's & + & + & + & - & - & + \\
\hline Terpenoid & $\mathrm{CHCl}_{3}+\mathrm{H}_{2} \mathrm{So}_{4}$ & + & + & + & - & + & - \\
\hline $\begin{array}{l}\text { Cardiac } \\
\text { glycoside }\end{array}$ & $\begin{array}{c}\mathrm{FeCl} 3+\text { glacial } \\
\text { acetic acid+ } \\
\mathrm{H}_{2} \mathrm{So}_{4}\end{array}$ & + & + & + & - & - & - \\
\hline Alkaloid & Mayer's test & + & + & + & - & - & + \\
\hline
\end{tabular}

$+=$ positive (present); - = negative (not present)

Table III. Quantity of phytochemical compounds in the extracts of two lines of G. sylvestre

\begin{tabular}{lcc}
\hline Compounds & MCL $(\mathbf{m g} / \mathbf{g})$ & ZMGL \\
\hline Saponin & 5.60 & 5.20 \\
Tannin & 0.10 & 0.40 \\
Flavonoid & 28.00 & 35.00 \\
Carbohydrate & 930.00 & 470.00 \\
Alkaloid & 120.00 & 109.00 \\
Protein & 0.30 & 0.27 \\
Phenol & 1.20 & 0.51 \\
Free radical activity & 17.00 & 35.00 \\
\hline
\end{tabular}

MCL - Big-leafed variety; ZMGL-Small-leafed variety

Table IV. Showing physicochemical analysis of the two line of G. sylvestre leaf extracts.

\begin{tabular}{lcc}
\hline Physiochemical property & MCL $\mathbf{( g m / g )}$ & ZMGL $\mathbf{( g m / g )}$ \\
\hline Total ash & 4.00 & 1.80 \\
Acid insoluble ash & 1.17 & 1.12 \\
Water soluble extract & 0.06 & 0.68 \\
Ether soluble extract & 0.66 & 0.45 \\
pH value & 5.90 & 5.00
\end{tabular}

MCL -Big-leafed variety; ZMGL- Small-leafed variety

Meanwhile, detailed and systematic pharmacognostical evaluation of the varieties may give valuable information for the future studies as opined by Kanetkar et al., (2004).

The results for physiochemical parameters estimated are presented (Table IV). Estimation of ash value and extractive value from dried leaves of the two varieties showed that MCL contained higher proportion of ash $(4.0 \mathrm{mg} / \mathrm{g})$ and ZMGL had low ash content of $1.8 \mathrm{mg} / \mathrm{g}$. The acid insoluble ash was also higher in MCL $(1.17 \mathrm{mg} / \mathrm{g})$ than ZMGL with $1.12 \mathrm{mg} / \mathrm{g}$ of acid insoluble ash. The water soluble extracts of ZMGL was more soluble in water $(0.68 \mathrm{mg} / \mathrm{g})$ than extracts of MCL $(0.06 \mathrm{mg} / \mathrm{g})$. Physiochemical constituent such as ash value is significant in phytochemical evaluation as it gives an idea of the inorganic composition and other impurities present in the extracts. Extractive values could therefore be useful for the determination of purity of medicinal products as opined (Mukherjee, 2002). 
Table V. Gymnemic acid Rf value estimation by TLC determination using different methods

\begin{tabular}{ccccccccc}
\hline \multirow{2}{*}{$\begin{array}{c}\text { No. } \\
\text { of spot }\end{array}$} & \multicolumn{2}{c}{ Method 1 } & \multicolumn{2}{c}{ Method 2 } & \multicolumn{2}{c}{ Method 3 } & \multicolumn{2}{c}{ Method 4 } \\
\cline { 2 - 9 } & MCL & ZMGL & MCL & ZMGL & MCL & ZMGL & MCL & ZMGL \\
\hline 1 & 0.17 & 0.34 & 0.07 & 0.31 & 0.64 & 0.81 & 0.63 & 0.65 \\
2 & 0.24 & 0.42 & 0.19 & 0.38 & 0.67 & 0.82 & 0.53 & 0.49 \\
3 & 0.34 & 0.48 & 0.32 & 0.44 & 0.91 & 0.89 & 0.46 & 0.34 \\
4 & 0.53 & 0.61 & 0.46 & 0.58 & 0.87 & 0.41 & 0.38 & 0.39 \\
5 & 0.19 & 0.83 & 0.90 & 0.77 & 0.30 & 1.9 & 0.36 & 0.42 \\
6 & 0.31 & --- & 0.15 & 0.79 & -- & -- & -- & - \\
7 & 0.42 & --- & 0.26 & --- & -- & -- & -- & - \\
8 & --- & --- & 0.38 & --- & -- & -- & -- & -- \\
9 & --- & -- & 0.90 & --- & -- & -- & -- & - \\
\hline
\end{tabular}

MCL - Big-leafed variety; ZMGL- Small-leafed variety

Table VI. Comparative hypoglycemic effect of leaf extracts of two lines of G. sylvetre and standard drug glibenclamide. (Blood glucose level $(\mathrm{mg} / \mathrm{dL}$ ) at $30 \mathrm{~min}$. time interval)

\begin{tabular}{|c|c|c|c|c|c|}
\hline & & Control & STTD & ZMGL & MCL \\
\hline $0 \mathrm{~min}$ & & $88.66 \pm 9.05$ & $82.60 \pm 9.37$ & $84.48 \pm 8.48$ & $82.96 \pm 2.82$ \\
\hline \multirow{2}{*}{ 30min } & Value & $168.83 \pm 21.47$ & $79.50 \pm 9.46^{*}$ & $74.50 \pm 13.43 *$ & $79.50 \pm 4.94^{*}$ \\
\hline & $\% \mathrm{R}$ & -90.42 & 3.77 & 11.81 & 4.17 \\
\hline \multirow{2}{*}{$60 \mathrm{~min}$} & Value & $119.51 \pm 15.80$ & $58.50 \pm 10.50 *$ & $60.00 \pm 4.24 *$ & $69.50 \pm 12.26^{*}$ \\
\hline & $\% \mathrm{R}$ & 29.21 & 26.41 & 19.46 & 12.5 \\
\hline \multirow{2}{*}{$90 \mathrm{~min}$} & Value & $119.50 \pm 18.94$ & $50.98 \pm 12.86^{*}$ & $54.50 \pm 14.84 *$ & $56.01 \pm 9.89 *$ \\
\hline & $\% \mathrm{R}$ & 0.00 & 2.85 & 10.09 & 19.41 \\
\hline \multirow{2}{*}{$120 \mathrm{~min}$} & Value & $112.66 \pm 22.44$ & $50.50 \pm 6.08 *$ & $51.02 \pm 5.65^{*}$ & $54.10 \pm 14.14 *$ \\
\hline & $\% \mathrm{R}$ & 5.73 & 0.94 & 6.38 & 3.41 \\
\hline \multirow{2}{*}{$150 \mathrm{~min}$} & Value & $104.01 \pm 23.37$ & $46.33 \pm 9.73 *$ & $46.40 \pm 9.92 *$ & $47.05 \pm 9.89 *$ \\
\hline & $\% \mathrm{R}$ & 7.67 & 8.25 & 9.06 & 13.03 \\
\hline
\end{tabular}

$\% \mathrm{R}^{*}=$ Percentage reduction in blood glucose level at $30 \mathrm{~min}$ interval; $* \mathrm{P}<0.01$, as compared to control group are significantly different (One Way ANOVA followed by Tukey's Multiple Comparison Test); STTDStandard drug glibenclamide; MCL-Big-leafed variety; ZMGL-Small-leafed variety

This may explains why most herbal pharmaceutical companies shows preference for the small-leaf line (ZMGL) due to its higher phytochemical yield potentials.

Analysis of gymnemic acid extracted from the leaves of the two lines of G. sylvestre by evaluation of the $\mathrm{Rf}$ values using Thin Layer Chromatography (TLC) and employing four different methods showed different Rf values for the two varieties (Table V). Generally, nine spot were considered for the chromatography, at spots 1-5, all the four methods produces different Rf values, but from spots 6-9, only method 2 had $\mathrm{Rf}$ values for ZMGL. Puratchimani and Jha, (2004) had earlier reported different $\mathrm{Rf}$ values for medicinal plant bioactive constituents extracted by different solvent methods. Other methods could not produce $\mathrm{Rf}$ values for most of the spots 6-9 (table V). Thin layer chromatography of the gymnemic acid indicated that some of $\mathrm{Rf}$ value are similar when compared with the reference 
Rf value and therefore implies that the purity of gymnemic acid obtained by such method is reliable.

Analysis of the blood samples from hyperglycemia induced whisker rats treated with extracts of G. sylvestre revealed similar with no significance difference to hypoglycemic activity of standard drug (glibenclamide) (Table $\mathrm{VI})$. There is significance difference in treatment efficiency with respect to control however, no significance difference was found in the efficiency of the extracts in lowering the blood glucose level in the experimental animals and this concurred with the report of Ankit, et al., (2010). Similar finding was earlier reported by Cretti et al. (2000) that plant extracts were efficient in lowering blood glucose. The hypoglycemia activities of gymnemic acid from the leaf extracts of the two varieties of $G$. sylvestre showed significant difference from untreated control and no significance difference with respect to treatment with a standard drug (glibenclamide). In fact after $30 \mathrm{~min}$ of glucose challenge in the experimental animals, extracts from ZMGL was found to have significant effect in reducing the blood glucose. Hence, the leaf extract from Gymnema sylvestre have similar efficiency in lowering blood glucose of whisker rats used in this study and this is in conformity and corroborated earlier reports (Babu et al., 2002; Nakamura et al., 2010, Krishna et al., 2012).

\section{CONCLUSION}

The use of plant extract to manage diseases and disorder has been long practiced by local folks mostly in the developing world. However, with economic regression and reported side effects of chemical drugs, the pendulum is gradually shifting toward the use of natural products which are locally available in abundance. This study evaluated the phytochemical characterization of compounds associated with Gymnema sylvestre using different solvents. It was discovered that water and methanol were the best solvents for extraction of phytochemical compounds from the plant. On the basis of the results of the present study, the gymneric acid obtained from the plant extract proved efficient for reducing glucose level in experimental animals. When compared to standard drug glibenclamide, similar hypoglycemic effects were achieved. However, considering the economic aspect, treatment and management of high level blood glucose is favoured by using extract of G. sylvesre.

\section{ACKNOWLEDGEMENTS}

The authors acknowledged the Management of Zandu Foundation for Health Care (ZFHC) Vapi India for providing the small-leafed varieties (ZMGL) of G. sylvestre used in this study

\section{REFERENCES}

Ajaiyeoba EO., 2000. Phytochemical and antimicrobial studies of Gynandropsis gynandra and Buchbolria coriaceae extracts. Af. J. Biom. Res.. 3(3): 161-165

Anki S., Sharma C., Aneja KR., Pahwa R., 2010. Gymnema sylvestre (Gurmar): A review. Der Pharmacia Letter, 2(1): 275-284.

Babu V., Gangadevi T., Subramaniam A., 2000. Antihyperglycemic activity of Cassia kleinii leaf extract in glucose fed normal rats and alloxan induced diabetic rats. Indian Journal of Pharmacology. 34: 409-415.

Bradford MM., 1976. A rapid and sensitive method for quantitation of microgram quantities of proteins utilizing proteindye binding. Anal of Biochemistry. 70: 248254

Cretti A., Brunato B., Zenti MG., Tosi F., Muggeo M., Bonora E., Bonadonna RC., 2000. A novel tool to assess B-cell function during the oral glucose tolerance test (OGTT). Diabetes. 49 (Suppl. 1): A89.

Grijesh, K.M., Pankaj, K.M. and Veeru P. (2009). Antidiabetic and hypolipidemic activity of Gymnema sylvestre in alloxan induced diabetic rats. Glob. J.Biotechnol. Biochem, 4 (1): 37-42.

Gunjan M., Ravindran M., Jana, GK., 2011. A review on some potential traditional phytomedicine with antidiabetic properties. Int. J. .Phyto.. 3: 448-458.

Gupta AK., 2003. Quality standards of Indian Medicinal Plants. E-journal of Ind. Med., 1(XVI): 262-265

Gzella AG., Dudek-Makuch M., Matławska I., 2012. DPPH Radical scavenging activity and phenolic compound content in different leaf extracts from selected 
Blackberry species. Acta Biologica Cracoviensia Series Botanica. 54(2): 32-38.

Hedge JE., Hofreiter BT., 1962. Carbohydrate Chemistry, (17 edn). Whistler RL, Miller IN. (eds) Academic Press: New York pp, 148-157.

Hellekant G., Ninomiya Y., Danilova V., 1998. Taste in chimpanzees. III: Labeled-line coding in sweet taste. Physiology and Behavior. 65(2): 191-200.

Hooper D., 1987. Isolation and antiviral activity of gymnemic acid. Pharm. Jour. Trans. 17: 867-868.

Indian Council of Medical Research, (ICMR). 2013. Database on ethnomedicinal plants of Western Ghats. http://www.icmr.nic.in/pinstitut e/belgaum/html/Research.html access Wed 18th Feb, 2014 19:24.

Joseph B., Jini D., 2010. Insight into the hypoglycemic effect of traditional Indian herbs used in the treatment of diabetes. Res. J. Med. Plant. 5(4): 352-376

Kanetkar PV., Laddha KS., Kamat MY., 2004. Gymnemic acids: a molecular perspective of its action on carbohydrate metabolism. Poster presented at the $16^{\text {th }}$ icfost meeting organized by cftri and $d f r l$. Mysore, India.

Khandelval KR., 2008. Practical Pharmacognosy. Pragati Books Pvt. Ltd. India. pp 157158.

Kokate A., 1999. Phytochemical Methods. Phototherapy. 78:126-129

Krishna RB., Sujitha R., Reddy R., Harika J., Swapna D., Jagadeeswara KR., 2012. An easy and simple method of isolation and purification of genomic DNA from the leaves of Gymnema sylvestre - an antidiabetic plant. Int. J.Life Scie. Pharm Res. 2(1): 15-20

Liu HM., Kiuchi F., Tsuda Y., 1992. Isolation and structure elucidation of Gymnemic acids; antisweet principles of Gymnema sylvestre. Chem. Pharm. 40: 1366-1375.

Mitra SK., Gopumadhavan S., Muralidhar TS., Anturlikar SD., Sujatha MB., 1995.
Effect of D-400 herbomineral preparation on lipid profile glycated haemoglobin and glucose tolerance in streptocine induced diabetes in rats. Ind $J$ Exp Bio. 33:798-800.

Mukherjee PK., 2002. Quality control of herbal drugs: An approach to evaluation of botanicals. Business Horizons, New Delhi, Pp.362

Nakamura Y., Tsumura Y., Tonogai Y., Shibata T., 1997. Contents of gymnemic acid in health foods using Gymnema sylvestre. J.Food Hygiene Society Japan. 38:178-184.

Obdoni BO., Ochuko PO., 2001. Phytochemical studies and comparative efficacy of the crude extracts of some homostatic plants in Edo and Delta States of Nigeria. Glob J Pure and Applied Sciences. 8: 203-208.

Ogawa Y., Sekita K., Umemura T., Saito M., Ono A., Kawasaki Y., Uchida O., Matsushima Y., Inoue T., Kanno J., 2004. Gymnema sylvestre leaf extract: A 52Week dietary toxicity study in whisker rats. Shokubin Eiseigaku Zasshi, 45(1): 818.

Puratchimani V., Jha, S., 2004. HPTLC standardization of Gymnema sylvestre R.Br. Using gymnestrogenin as references. Ind. J.Pharm. Scie. 66(2): 242-244

Sofowra A., 1993. Med. plants traditional medicine in Africa. Spectrum Books Ltd., Ibadan, Nigeria, pp. 191-289.

Trease GE., Evans WC., 2005. Pharmacognosy. (10 th edn). Harbcourt Publishers. WB Saunders Company Ltd. New York. pp 95-96.

Yadav RNS., Agarwal M., 2011. Phytochemical analysis of some medicinal plants J.Phytology. 3(12):10-14.

Ye WC., Zhang Q., Liu X., Che C., Zhao S., 2000. Oleanane saponins from Gymnema sylvestre Phytochemistry, 53: 893-899.

Zohary D., Hopf M., Weisse E., 2000. Domestication of plants in the old world, (4th edn). Oxford University Press: NY, pp 264 